Original Study

\title{
Advance Directive and End-of-Life Care Preferences Among Nursing Home Residents in Wuhan, China: A Cross-Sectional Study
}

\author{
Ping Ni PhD $(c)^{a}$, Jing Zhou BS ${ }^{a}$, Zhao Xi Wang BS ${ }^{a}$, Rong Nie $\mathrm{PhD}(\mathrm{c})^{\mathrm{a}}$, \\ Jane Phillips $\mathrm{PhD}^{\mathrm{b}}$, Jing Mao $\mathrm{PhD}^{\mathrm{a}, *}$ \\ a School of Nursing, Tongji Medical College, Huazhong University of Science and Technology, Wuhan, Hubei, China \\ ${ }^{\mathrm{b}}$ Faculty of Health, University of Technology Sydney, Sydney, Australia
}

Keywords:

End-of-life care

advance directive

nursing home

Chinese

\begin{abstract}
A B S T R A C T
Objectives: To describe Chinese nursing home residents' knowledge of advance directive (AD) and end-oflife care preferences and to explore the predictors of their preference for AD.

Design: Population-based cross-sectional survey.

Settings: Nursing homes $(\mathrm{n}=31)$ in Wuhan, Mainland Southern China.

Participants: Cognitively intact nursing home residents $(n=467)$ older than 60 years.

Measures: Face-to-face questionnaire interviews were used to collect information on demographics, chronic diseases, life-sustaining treatment, $\mathrm{AD}$, and other end-of-life care preferences.

Results: Most (95.3\%) had never heard of $\mathrm{AD}$, and fewer than one-third (31.5\%) preferred to make an $\mathrm{AD}$. More than half (52.5\%) would receive life-sustaining treatment if they sustained a life-threatening condition. Fewer than one-half (43.3\%) chose doctors as the surrogate decision maker about lifesustaining treatment, whereas most (78.8\%) nominated their eldest son or daughter as their proxy. More than half (58.2\%) wanted to live and die in their present nursing homes. The significant independent predictors of AD preference included having heard of AD before (odds ratio [OR] 9.323), having definite answers of receiving (OR 3.433) or rejecting (OR 2.530) life-sustaining treatment, and higher Cumulative Illness Rating Scale score (OR 1.098).

Conclusions: Most nursing home residents did not know about AD, and nearly one-third showed positive attitudes toward it. AD should be promoted in mainland China. Education of residents, the proxy decision maker, and nursing home staff on AD is very important. Necessary policy support, legislation, or practice guidelines about AD should be made with flexibility to respect nursing home residents' rights in mainland China.
\end{abstract}

(c) 2014 AMDA - The Society for Post-Acute and Long-Term Care Medicine.
With the aging of China's population, the demand for nursing home care is increasing. ${ }^{1}$ In Wuhan, a southern city in Hubei province, Mainland China, there are approximately 9.79 million people. ${ }^{2}$ The number of people older than 65 years in China is projected to increase from its current level of $8.9 \%^{3}$ to $23.0 \%$ by $2050 .^{4}$ Although few $(1.49 \%)$ older people currently live in nursing homes in mainland China, ${ }^{4}$ it is anticipated that a combination of China's "4-2-1" (1-child policy) or " $4-2-2$ " (some couples can have 2 children if only 1 or neither of the pair has siblings) family structure and industrialization $^{5}$ will see larger numbers of older people moving into nursing

The authors declare no conflicts of interest

This study was funded by the Fundamental Research Funds for the Central Universities, Huazhong University of Science and Technology (project grant number: 2012QN206).

* Address correspondence to Jing Mao, PhD, School of Nursing, Tongji Medical College, Huazhong University of Science and Technology, Number 13, Hangkong Road, Qiaokou District, Wuhan, Hubei, China.

E-mail address: maojing@hust.edu.cn (J. Mao). homes. ${ }^{6}$ Although nursing home residents are frailer than those living in their own homes, ${ }^{6}$ few studies have investigated the end-of-life care preferences of older Chinese people living in nursing homes. ${ }^{7}$ A recent study involving older Chinese people living in Hong Kong nursing homes found that most did not desire cardiopulmonary resuscitation (CPR) (61\%) or artificial nutrition or hydration (74\%) to be initiated. ${ }^{7}$ Another Hong Kong study identified that many nursing home residents were uncertain or uncomfortable when asked about stating their preferences for life-sustaining treatment, with many leaving this question unanswered.

In traditional Chinese culture, death is a very sensitive issue, and a topic to be avoided, with those who do mention death considered sacrilegious. $^{8}$ Most older Chinese people consult their relatives, especially their oldest son, before making health care decisions. For example, traditional Taiwanese believe their eldest son is responsible for arranging the rest of their life. ${ }^{9}$ In a rapidly developing country like China, it is challenging to integrate traditional values and advance care planning processes into the existing health care system. 
Globally, there is a push to ensure that more people prospectively document their end-of-life care preferences, often in the form of an advance directive (AD). ${ }^{10-12} \mathrm{An} A \mathrm{D}$ is a legal document that outlines a person's care preferences and wishes, should their decision-making ability be diminished as a result of a critical illness or cognitive impairment. ${ }^{13,14}$ Unlike other parts of the developed world (ie, United States, ${ }^{15}$ Netherlands, ${ }^{16}$ Australia, ${ }^{12}$ United Kingdom, ${ }^{11}$ and Singapore ${ }^{17}$ ), the concept of $\mathrm{AD}$ is still relatively new in mainland China. However, in other parts of China, there is growing interest and concern about the need for better end-of-life care for terminally ill older patients, which is reflected in various recent policy initiatives. For example, in June 2007, the Hong Kong Law Reform Commission issued a Consultation paper on "Substitute Decision Making and AD," detailing that doctors must comply with a patient's AD and end-of-life preferences. ${ }^{18}$ In Taiwan, the Hospice-Palliative Care Act (2002) aims to ensure that the end-of-life medical wishes of patients are respected and end-of-life care is provided in accordance with recommended clinical guidelines. ${ }^{19,20}$ In mainland China, palliative care is developing slowly and there is currently no case law regarding AD. In mid-2013, the Beijing Advance Directive Promotion Association was established with the approval of the Beijing Civil Affairs Bureau. ${ }^{21}$ Charged by the Beijing Ministry of Health, this organization aims to promote the uptake of $\mathrm{AD}$ in China, inform Chinese people of their rights to prospectively define their end-of-life care preferences, and to enhance care of the dying. ${ }^{21}$ Given the paucity of information and limited published data on $\mathrm{AD}$ and end-of-life care preferences among older adults in mainland China, this study sought to describe mainland Chinese nursing home residents' knowledge of AD and their end-oflife care preferences, and to identify predictors of their $\mathrm{AD}$ preferences.

\section{Methods}

\section{Study Design and Participants}

This study adopted a cross-sectional study design using a cluster sampling method. Ethical approval of the research protocol was granted by the institutional review board of the Huazhong University of Science and Technology as well as from all institutional review boards of participating nursing homes. This study was conducted over an 11-month period, from December 1, 2012, to October 31, 2013.

The study involved 8 of 13 regions of Wuhan (Wu Chang, Qiao Kou, Jiang Han, Jiang An, Hong Shan, Dong Xi Hu, Qing Shan, and Han Yang), mainland China. All nursing homes in these regions were invited to be involved in the study. Once the nursing homes agreed to participate, all elderly residents in these nursing homes were screened for eligibility, using the following inclusion criteria: older than 60 years, Chinese-speaking, and made 3 or less errors on the Chinese Version-Short Portable Mental Status Questionnaire (SPMSQ). ${ }^{22}$ Residents with known psychiatric or cognitive problems and/or communication difficulties were excluded from the study.

\section{Data Collection}

A member of the research team, a trained nurse facilitator, collected the quantitative data, including demographic data from participants during a 45-minute face-to-face interview and administered the following validated instruments (Table 1). The Chinese Version of the Cumulative Illness Rating Scale (CIRS) ${ }^{6}$ was used to capture comorbid conditions, which were confirmed by the medical record. Physical functional status was collected using the Chinese version of Personal Activity of Daily Living (P-ADL) and Instrumental Activity of Daily Living (I-ADL); the score of P-ADL or I-ADL was the sum value of all 8 items in each scale which range from 8 to $24 .^{23}$ The Quality-of-Life Concerns in the End-of-Life Questionnaire (QOLC-E) was also administered. ${ }^{24}$ Participants' preferences for various lifesustaining treatment were elicited by asking the following question: "If you were severely ill or even in a life-threatening condition in which life-sustaining treatment could only help you to sustain your life but cannot recover your health, would you like to accept it?" Participants were also asked other specific questions exploring their preferences related to AD and end-of-life care.

\section{Data Analysis}

The Statistical Package for Social Sciences (SPSS) version 17.0 for Windows (IBM SPSS Statistics, IBM Corporation, Chicago, IL) was used for the quantitative data analyses. The participants' characteristics and their responses to each of the questions were analyzed by descriptive statistics first. For the question "If you have the chance to make an $A D$, would you be willing to make it?" (refer to question 2 in Table 2), the 4 possible responses were merged accordingly: "Willing" and "Fairly willing" (Willing), "Reluctant" and "Fairly reluctant" (Reluctant). Chisquare test and $t$ test were used for categorical and continuous variables, respectively. Bivariate analyses were used to examine the associations of sociodemographic characteristics, chronic diseases, and other factors with the preference for AD. Factors significant previously in univariate analyses were included in the binary forward (likelihood ratio) logistic regression analyses models (binary logistic regression is the statistics method, forward: likelihood ratio is the variable selection method), all adjusted for age and sex. The dependent variable was the preference for $\mathrm{AD}$ and the independent variables were factors with $P<.05$ in previous bivariate analyses.

\section{Results}

A total of 31 (62\%) of 50 nursing homes participated in the study. Of the 501 participants identified as eligible to participate, 489 (97.6\%) gave written informed consent. Of the 489 consenting participants, 22 interviews were subsequently ceased, as the participants became too distressed $(n=12)$ or too tired $(n=10)$ to continue, leaving 467 participants.

\section{Demographics}

The demographic characteristics of the 467 participants are reported in Table 1. No significant difference was found in sex, mean age, and education level between those who agreed $(n=489)$ and refused $(\mathrm{n}=12)$ to participate in the study. Of the recruited participants, more than half $(59.5 \%)$ were women, and the mean age $( \pm S D)$ was $77.0 \pm 8.527$ years. Most were widowed (85.7\%) and most (85.4\%) lived in private nursing homes. Half $(52.9 \%)$ had health insurance. Nearly three-quarters (73.7\%) were educated to the elementary school level or higher, whereas a quarter (26.3\%) had never been to school. Nearly all perceived they had "good/general good relationship with family" (91.9\%) and other residents (86.5\%). In accordance with Chinese culture, half $(50.1 \%)$ had a belief that their ancestors lived in another world, and they would be protected by the ancestors if they remember and memorialize them ("ancestor worship"). Most (67.9\%) self-rated their health as being "generally good," with hypertension (48.0\%), insomnia (18.2\%), and stroke (18.0\%) ranked as the top 3 most common chronic diseases/conditions. The QOLC-E score for the sample was (mean $\pm \mathrm{SD}$ ) $3.23 \pm 0.48$, the I-ADL and P-ADL scores were $12.91 \pm 4.27$ and $20.78 \pm 4.74$, respectively, and the CIRS score was $4.23 \pm 2.98$ (Table 1 ).

\section{Knowledge and Preferences for $A D$ and End-of-Life Care}

Most (95.3\%) had never heard of $A D$, and fewer than a third (31.5\%) were "willing/fairly willing" to make an $\mathrm{AD}$, and the main 
Table 1

Characteristics of Nursing Home Residents $(\mathrm{n}=467)$

\begin{tabular}{|c|c|c|}
\hline $\begin{array}{l}\text { Social and Demographic } \\
\text { Characteristics }\end{array}$ & & \\
\hline Age, $\mathrm{y}, \mathrm{n}(\%)^{*}$ & $60-74$ & $174(37.3)$ \\
\hline & $75-89$ & $266(57.0)$ \\
\hline & $90-110$ & $27(5.8)$ \\
\hline Sex, n (\%) & Male & $189(40.5)$ \\
\hline & Female & $278(59.5)$ \\
\hline Type of nursing home, $\mathrm{n}(\%)$ & Government organized & $23(4.9)$ \\
\hline & Nongovernment organized & $45(9.6)$ \\
\hline & Private & $399(85.4)$ \\
\hline Marital status, n (\%) & $\begin{array}{l}\text { Living together/Single/ } \\
\text { Divorced/Separated/Married }\end{array}$ & $67(14.3)$ \\
\hline & Widowed & $400(85.7)$ \\
\hline Educational level, n (\%) & Never been to school & $123(26.3)$ \\
\hline & Elementary or more & $344(73.7)$ \\
\hline Whether have health & No & $220(47.1)$ \\
\hline insurance, n (\%) & Yes & $247(52.9)$ \\
\hline Government subsidy, n (\%) & No & $41(8.8)$ \\
\hline & $\begin{array}{l}\text { Disability allowance/ } \\
\text { government subsidy for } \\
\text { the poor/old age allowance/ } \\
\text { others }\end{array}$ & $100(21.4)$ \\
\hline & Retirement pension & $326(69.8)$ \\
\hline Do you worry about financial & No worries & $413(88.4)$ \\
\hline condition, n (\%) & Worried & $54(11.6)$ \\
\hline Social contacts, n (\%) & Always & $237(50.7)$ \\
\hline & Rare/No Contact & $230(49.3)$ \\
\hline Support received, n (\%) & Enough & $286(61.2)$ \\
\hline & No/not enough & $181(38.8)$ \\
\hline Do medical staff meet your & Rarely/Occasionally & $223(47.8)$ \\
\hline request? n (\%) & Often/Always & $244(52.2)$ \\
\hline Have a feeling of being & Never & $280(60.0)$ \\
\hline forgotten by families, $\mathrm{n}(\%)$ & Sometimes/Often & $187(40.0)$ \\
\hline Relationship with family, n (\%) & Good/Generally good & 429 (91.9) \\
\hline & Bad/Generally bad & $38(8.1)$ \\
\hline Relationship with other & Good/Generally good & $404(86.5)$ \\
\hline residents, n (\%) & Bad/Generally bad & $63(13.5)$ \\
\hline Can you receive favorite food & Rarely/No & $253(54.2)$ \\
\hline in nursing home? n (\%) & Always & $214(45.8)$ \\
\hline Religion belief, n (\%) & No religious belief & $190(40.7)$ \\
\hline & Buddhism & $25(5.4)$ \\
\hline & Taoism & $1(0.2)$ \\
\hline & Catholicism & $4(0.9)$ \\
\hline & Christianity & $11(2.4)$ \\
\hline & Ancestor worship & $234(50.1)$ \\
\hline & Other & $2(0.4)$ \\
\hline Self-rated health, $\mathrm{n}(\%)$ & Poor & 65 (13.9) \\
\hline & Generally good & $317(67.9)$ \\
\hline & Good & $85(18.2)$ \\
\hline Top 9 chronic diseases, $\mathrm{n}(\%)$ & Hypertension & $224(48.0)$ \\
\hline & Insomnia & $85(18.2)$ \\
\hline & Stroke & $84(18.0)$ \\
\hline & Constipation & $80(17.1)$ \\
\hline & Hearing problem & $68(14.6)$ \\
\hline & Blurred vision & $63(13.5)$ \\
\hline & Diabetes & $62(13.3)$ \\
\hline & Arthritis & $40(8.6)$ \\
\hline & Gout & $36(7.7)$ \\
\hline QOLC-E score, mean \pm SD & SIS (Max 10) & $7.03 \pm 1.28$ \\
\hline & Physical discomfort (Max 4) & $3.63 \pm 0.53$ \\
\hline & Negative emotions (Max 4) & $3.58 \pm 0.77$ \\
\hline & Existential distress (Max 4) & $3.50 \pm 0.93$ \\
\hline & Care and support (Max 4) & $3.14 \pm 0.49$ \\
\hline & Value of life (Max 4) & $2.99 \pm 1.00$ \\
\hline & Food-related concerns (Max 4) & $2.55 \pm 0.69$ \\
\hline & Mean score of QOLC-E (Max 4) & $3.23 \pm 0.48$ \\
\hline Functional status, mean \pm SD & Overall scores of I-ADL & $12.91 \pm 4.27$ \\
\hline & Overall scores of P-ADL & $20.78 \pm 4.74$ \\
\hline CIRS score, mean \pm SD & Overall scores of CIRS & $4.23 \pm 2.98$ \\
\hline
\end{tabular}

CIRS, Cumulative Illness Rating Scale; I-ADL, Instrumental Activity of Daily Living Max, maximum; P-ADL, Personal Activity of Daily Living; QOLC-E, Quality-of-life Concerns in the End-of-life Questionnaire; SIS, Single Item Scale.

*Mean: 77, SD 8.527. reason cited was "It is good to make one when I am cognitively intact" (44.2\%). The main reason people cited for being "reluctant/fairly reluctant" to make an $\mathrm{AD}$ was that they were "Not familiar with it" (65.5\%). Of note, most (91.2\%) wanted to be informed of their diagnosis if they developed a terminal condition. Although most (81.6\%) had never previously received life-sustaining treatment, just more than half (52.5\%) indicated they would elect to receive life-sustaining treatment if they sustained a life-threatening condition; the other half would reject this level of treatment $(24.2 \%)$ or "did not know" (23.3\%). Fewer than a half (43.3\%) preferred to have their physician to be the surrogate decision maker (acting agent who only decides for some specific health care decisions) about life-sustaining treatment decisions, whereas most (78.8\%) nominated their eldest son or daughter as their proxy (authorized surrogate who has durable power of attorney to make all health care decisions for the patient). More than half $(58.2 \%)$ wanted to live and die in their present nursing homes, whereas almost a quarter (23.1\%) would prefer to live and die at home (Table 2).

\section{Predictors of Nursing Home Residents' Preference for an $A D$}

Bivariate analyses identified religious belief, attitudes toward lifesustaining treatment, awareness of $\mathrm{AD}$, and CIRS score as significant predictors of $\mathrm{AD}$ preference. In the final age- and sex-adjusted binary forward logistic regression model, the following factors were the significant independent predictors of preference for an AD: heard of AD before (odds ratio [OR] 9.323), or have definite answers of receiving (OR 3.433) or rejecting (OR 2.530) life-sustaining treatment under hypothetical severe conditions and higher CIRS score (OR 1.098) (Table 3).

\section{Discussion}

\section{Preferences for an AD Among Nursing Home Residents}

This study provides valuable insights into Chinese residents' understanding of $\mathrm{AD}$ and their preparedness to discuss their end-of-life care preferences, especially given the paucity of end-of-life research undertaken with this population. In our study, although few nursing home residents in Wuhan, mainland China, had heard of $A D$, almost a third showed positive attitudes toward being able to prospectively document their treatment wishes. These results are similar to another study, which found $37.2 \%$ of elderly Chinese Singaporeans who attended a day care center agreed that making an $\mathrm{AD}$ would be necessary. ${ }^{25}$ A 2012 study by Ivo et al $^{26}$ also found that $79.3 \%$ of mainland Chinese patients with cancer acknowledged the need for a legally authorized "AD" for medical decision making if they became unconscious or could not communicate for some other reason. These findings are somewhat different from a qualitative study, which found that Canadian Chinese seniors felt that projecting one's wishes and feelings into a future and hypothetical situation was unrealistic and that $\mathrm{AD}$ has no effect on the inevitable cycle of life. ${ }^{27}$ As this study was conducted more than a decade ago, these results may reflect the participants' cultural assimilation and exposure to a Western health care system.

\section{Policy Influences}

In 2011, Chu et $\mathrm{al}^{7}$ found that approximately $88 \%$ of Hong Kong Chinese nursing home residents were in favor of having an AD, which was much higher than the $31.5 \%$ found in our study. However, there were key differences in terms of both culture and public policy 
Table 2

Knowledge of AD, AD and End-of-Life Preferences Among Chinese Nursing Home Residents $(\mathrm{n}=467)$

\begin{tabular}{|c|c|c|}
\hline Questions & & $\mathrm{n}(\%)$ \\
\hline \multirow[t]{2}{*}{ Have you heard of AD before? } & No & $445(95.3)$ \\
\hline & Yes & $22(4.7)$ \\
\hline \multirow[t]{2}{*}{ If you have the chance to make an $\mathrm{AD}$, Would you be willing to make it? } & Willing/Fairly willing & $147(31.5)$ \\
\hline & Reluctant/Fairly reluctant & $320(68.5)$ \\
\hline \multirow[t]{3}{*}{ Reasons of being willing to make an $\mathrm{AD}$. } & It is good to make one when I am cognitively intact & $65(44.2)$ \\
\hline & It is good to make my family members know my wishes earlier & $57(38.8)$ \\
\hline & Other reasons & $25(17.0)$ \\
\hline \multirow[t]{5}{*}{ Reasons of being reluctant to make an AD. } & Not familiar with it & $210(65.5)$ \\
\hline & My family can make all the decisions for me & $74(23.1)$ \\
\hline & It is no use even I make it & $19(6.0)$ \\
\hline & It is too early to make one & $10(3.2)$ \\
\hline & Others & $7(2.1)$ \\
\hline \multirow[t]{2}{*}{ Do you wish to be informed of the real diagnosis and prognosis of a disease? } & No & $41(8.8)$ \\
\hline & Yes & $426(91.2)$ \\
\hline \multirow[t]{2}{*}{ Have received life-sustaining treatment before? } & No & $381(81.6)$ \\
\hline & Yes & $86(18.4)$ \\
\hline \multirow[t]{2}{*}{ Have you seen others rescued before? } & No & $373(79.9)$ \\
\hline & Yes & $94(20.1)$ \\
\hline \multirow{3}{*}{$\begin{array}{l}\text { If you were severely ill or even in a life-threatening condition in which life-sustaining } \\
\text { treatment could only help you to sustain your life but cannot recover your health, } \\
\text { would you like to accept it? }\end{array}$} & Reject life-sustaining treatment & $113(24.2)$ \\
\hline & Accept life-sustaining treatment & $245(52.5)$ \\
\hline & No comment & $109(23.3)$ \\
\hline \multirow[t]{3}{*}{ Reasons for accepting life-sustaining treatment } & One should try when there is a chance & $203(82.9)$ \\
\hline & I want to live longer & $26(10.6)$ \\
\hline & Other reasons & $16(6.5)$ \\
\hline \multirow[t]{4}{*}{ Reasons for rejecting life-sustaining treatment } & I am already old enough and did not want to prolong life & $52(46.0)$ \\
\hline & $\begin{array}{l}\text { Distrust in the effectiveness/discomfort/complications for these } \\
\text { treatments }\end{array}$ & $34(30.2)$ \\
\hline & I do not want to be a burden to my family & $13(11.5)$ \\
\hline & Other reasons & $14(12.4)$ \\
\hline \multirow[t]{9}{*}{ Who should be the surrogate decision maker about life-sustaining treatment? } & Doctors & $202(43.3)$ \\
\hline & Family members & $90(19.3)$ \\
\hline & Myself & $85(18.2)$ \\
\hline & It depends & $31(6.6)$ \\
\hline & Doctors and myself & $20(4.3)$ \\
\hline & Family members and doctors & $14(3.0)$ \\
\hline & Family members, doctors, and myself & $12(2.6)$ \\
\hline & Family members and myself & $11(2.4)$ \\
\hline & Nursing home manager & $2(0.4)$ \\
\hline \multirow[t]{7}{*}{ Whom will you appoint as your proxy if you become unconscious? } & Eldest son/daughter & $368(78.8)$ \\
\hline & Other family members & $37(7.9)$ \\
\hline & Nobody & $30(6.5)$ \\
\hline & Nursing home manager & $13(2.8)$ \\
\hline & Others & $9(1.9)$ \\
\hline & Spouse & $6(1.3)$ \\
\hline & Friends & $4(0.9)$ \\
\hline \multirow[t]{4}{*}{ Where do you want to live your rest life and die? } & Present nursing home & $272(58.2)$ \\
\hline & My home & $108(23.1)$ \\
\hline & Hospital & $3(0.6)$ \\
\hline & It depends/unknown & $84(18.1)$ \\
\hline \multirow[t]{6}{*}{ What do you care about most now? } & Health & $180(38.5)$ \\
\hline & Family members & $51(10.9)$ \\
\hline & State affairs/environment/social welfare & $31(6.6)$ \\
\hline & Daily life & $13(2.8)$ \\
\hline & Others & $26(5.6)$ \\
\hline & Nothing & $166(35.5)$ \\
\hline \multirow[t]{6}{*}{ What medical care do you want now? } & Medical cost can be decreased & $184(39.4)$ \\
\hline & Effective treatment & $68(14.6)$ \\
\hline & Higher quality of life & $37(7.9)$ \\
\hline & Periodic physical examination/others & $31(6.6)$ \\
\hline & Having insurance & $9(1.9)$ \\
\hline & Nothing & $138(29.6)$ \\
\hline
\end{tabular}

$\mathrm{AD}$, advance directive.

regulations between the 2 studies. In Hong Kong, the consultation paper "Substitute Decision Making and Advance Directives" ${ }^{18}$ actively encourages health professionals to spend more time discussing $A D$ with nursing home residents, so that they are familiar with the principles and importance of advance care planning. In mainland China, although there has been the establishment of an agency to popularize $\mathrm{AD},{ }^{21}$ a lack of necessary policy support, legislation, formal educational training, or practice guidelines makes it difficult to integrate AD and/or end-of-life care practices in the clinical setting. As a result, symptom control and palliative care is yet to be promoted as a practice specialty or as an area for clinical research. ${ }^{28}$ A combination of busy clinical practices, where death is regarded as unlucky and these conversations may be viewed by patients as taking away their hope and hastening death, makes it difficult to determine the ideal time to initiate $\mathrm{AD}$ discussions in mainland China. The lack of awareness of AD among residents who participated in our study suggests a need for enhancing 
Table 3

Binary Logistic Regression Model Predicting AD ( $\mathrm{n}=467)$

\begin{tabular}{|c|c|c|c|c|}
\hline $\begin{array}{l}\text { Independent Predictors } \\
\text { Adjusted for Age and Sex } \\
\text { (Willing vs Reluctant) }\end{array}$ & OR & $95 \% \mathrm{CI}$ & $P$ & $\beta(\mathrm{SE})$ \\
\hline $\begin{array}{l}\text { Have you heard of AD } \\
\text { previously? (Yes vs No) }\end{array}$ & 9.323 & $2.620-33.174$ & $.001^{*}$ & 0.648 \\
\hline $\begin{array}{l}\text { If you were severely ill or } \\
\text { even in a life-threatening } \\
\text { condition in which life- } \\
\text { sustaining treatment could } \\
\text { only help you to sustain } \\
\text { your life but cannot recover } \\
\text { your health, would you like } \\
\text { to accept it? }\end{array}$ & & & $.001^{*}$ & \\
\hline $\begin{array}{l}\text { - Accept life-sustaining } \\
\text { treatment }\end{array}$ & 3.433 & $1.752-6.727$ & $.000^{\dagger}$ & 0.343 \\
\hline $\begin{array}{l}\text { - Reject life-sustaining } \\
\text { treatment }\end{array}$ & 2.530 & $1.176-5.441$ & $.018^{\ddagger}$ & 0.391 \\
\hline - No comment & $\begin{array}{l}1.000 \\
\text { (reference) }\end{array}$ & & & \\
\hline CIRS score & 1.098 & $1.017-1.186$ & $.016^{\ddagger}$ & 0.039 \\
\hline
\end{tabular}

$\mathrm{AD}$, advance directive; $\mathrm{CI}$, confidence interval; CIRS, cumulative illness rating scale; OR, odds ratio.

${ }^{*} P<.01$.

${ }^{\dagger} P<.001$.

${ }^{\ddagger} P<.05$.

public educational programs and promotion of $\mathrm{AD}$ and potentially considering legislation to support AD.

\section{End-of-Life Care Preferences Among Nursing Home Residents}

Similar to Ivo and colleagues ${ }^{26}$ findings, most Chinese nursing home residents in our study also wanted to be informed about their diagnosis and prognosis. The proportion that rejected active treatment near the end of life was much lower than those reported in a Hong Kong Chinese nursing home study, which found that more than half of the residents did not want CPR and artificial nutrition to be started. ${ }^{7}$ However, unlike our study, the Hong Kong study did not explore the residents' life-sustaining treatment experiences, ${ }^{7}$ which may have contributed to these different results. In another study, 92\% of Canadian caregivers who had provided end-of-life care to family indicated that they would in the future reject futile life-sustaining treatment to extend life, ${ }^{29}$ suggesting that people with previous life-sustaining treatment experiences may be more likely to reject this level of intervention in the future, but this notion needs to be further explored.

In mainland China, patients have to pay for their own medical costs, which may be another reason for declining life-sustaining treatment. In 2012, Ivo et $\mathrm{al}^{26}$ found that only 55.7\% of Chinese patients with cancer wanted to continue artificial ventilation, but this rate increased to $72.1 \%$ "if ventilation was free." In our study, only half of the residents had health insurance, which may have influenced their decisions about future life-sustaining treatment.

Reflecting Confucian teaching, the eldest son or daughter was favored by most elder residents as their proxy. The role of the eldest son or daughter is imbued within Chinese religious beliefs, filial piety strongly influences decision making in China. ${ }^{30}$ In accordance with tradition, the eldest son or daughter is obliged by filial piety to do everything to prolong the older person's life, the opinions of family members and health care professionals take precedence over personal opinions or preferences. ${ }^{31}$

In terms of preferred place of dying, 10 years ago, Liu and $\mathrm{Gu}^{32}$ reported that nearly $90 \%$ of Chinese decedents older than 80 died at home, whereas our study found that fewer than a quarter (23.1\%) wanted to die at home. The increasing number of single households in mainland China and fewer households comprising more than 1 generation means that fewer older people have access to the necessary family caregiver support to be able to die at home. The burden of needing sustained home care and its associated financial cost has been cited as a reason why many palliative care patients in Japan chose to die at a place other than home. ${ }^{33}$ Dying in a Chinese hospital is now more expensive than dying at home and/or in a nursing home, which may influence the preferred place of death. Previously, it was thought that community-based end-of-life care might not be acceptable to older people in mainland China, because of traditional expectations that their descendents, especially their son, will care for them, and the shame and fear that their descendents will be regarded as unfilial by the community neighbors, if they fail to do so. Yet, our study found that more than half of all residents nominated their present nursing homes as their preferred place to die, reinforcing the need to support the future development of end-of-life care in the Chinese nursing homes, to ensure a resident's preferences are respected and prospectively documented in an $\mathrm{AD}$.

\section{Predictors of $A D$ Preference Among Nursing Home Residents in Mainland China}

The strongest predictor for making an AD was having previously heard about it, which is consistent with previous research that communication about end-of-life care facilitates peoples' decisions to complete an $\mathrm{AD},{ }^{34}$ reinforcing the need to continue to promote $\mathrm{AD}$ in mainland China using targeted education and media campaigns. Future research about interventions that increase $\mathrm{AD}$ completion rates in China is needed, as well as exploring the relationship of $A D$ preferences and completion rates.

The second predictor of $\mathrm{AD}$ was being able to accept or reject lifesustaining treatment, suggesting that the residents who can make definite decisions about their future care preferences may have more autonomy compared with the people who gave indefinite answers. Kelley et al also found that Latinos who had greater autonomy were more likely to have completed an $\mathrm{AD} .^{35}$

The third predictor of $A D$ was people with higher CIRS score were more likely to complete an $\mathrm{AD}$, which has been found in similar studies. ${ }^{36-39}$ Sahm et $\mathrm{al}^{36}$ found that deteriorating health was associated with increasing willingness to make an AD. Ko et $\mathrm{al}^{37}$ found that Korean Americans believed completion of an AD was unnecessary unless one has a serious illness, and planning for end of life was considered to be appropriate only for those in poor health. Gordon and Shade ${ }^{38}$ found that severity of illness was positively associated with $\mathrm{AD}$ completion rate. Tajouri et $\mathrm{al}^{39}$ also found that patients with chronic diseases were more prone to have an AD. These results suggest that doctors and nurses should broach the subject of end-of-life treatment preferences well before the residents' conditions become worse, so they have time to consider their AD preferences in advance of their conditions deteriorating.

Unlike other studies, which have found that older people were more likely to complete an $\mathrm{AD},{ }^{40,41}$ we did not find any relationship between age and $\mathrm{AD}$ preference. This may reflect Chinese culture, where Confucianism plays an important role with older residents relying on their family for care and decision making. In Chinese culture, relative power is usually considered more important than patient autonomy, so older Chinese residents often prefer that their family makes all care or treatment decisions. Although the concept of creating an $\mathrm{AD}$ is founded on patient autonomy, it ignores the influence of family members and larger social networks. Local factors, ${ }^{42}$ such as culture differences or ideology, may play a large part in prevalence of AD.

Similar to previous studies, ${ }^{7}$ gender, educational levels, religions, self-rated heath status, and financial status of nursing home residents 
were not found to be predictors of residents' preference for making an AD. Although AD may not be considered culturally appropriate by all older Chinese, policy makers need to identify strategies that allow flexibility to respect and protect rights of residents and their families, while also promoting $\mathrm{AD}$ as a viable option to record end-of-life care preferences.

\section{Limitations of the Study}

There are several limitations with this study, namely the sample size and that privacy issues prevent us from recruiting participants through population-based random sampling. Second, we excluded participants with more than 3 errors on the SPMSQ so our findings only reflect the views of older Chinese people with no obvious signs of cognitive impairment living in mainland China nursing homes, so may not be generalizable to other populations.

\section{Conclusions}

This study provides insight into AD and end-of-life care preferences among nursing home residents living in mainland China and further highlights that residents who have heard of $\mathrm{AD}$ and have higher CIRS scores are more willing to make an AD. There are opportunities to promote AD more widely among nursing homes in mainland China, but this will require targeted education of residents, their proxy decision makers, and nursing home staff. The prospective documentation of residents' treatment preferences will help ensure that nursing home doctors and nurses, proxy, and family members adhere to the residents' end-of-life care wishes. Policy or law about $\mathrm{AD}$ should be made with flexibility to respect residents' rights in mainland China.

\section{Acknowledgments}

We express our gratitude to Professor Pang MCS of the nursing school, the Hong Kong Polytechnic University, for her input in the pilot project, and Yin Ping of the School of Public Health, Huazhong University of Science and Technology, for his contribution in the data statistics, as well as all the participating nursing homes for their help.

\section{References}

1. National Bureau of Statistics of China. Population survey of China. Available at: http://www.stats.gov.cn/was40/gjtjj_detail.jsp?searchword=\%D1\%F8\%C0\%CF\% D4\%BA\&channelid=6697\&record=16/. Accessed June 27, 2012.

2. Statistics Information of Wuhan. The sixth population survey of Wuhan 2010. Available at: http://www.whtj.gov.cn/Article/ShowArticle.aspx?id=6417. Accessed June 27, 2012.

3. National Bureau of Statistics of China. The sixth population survey of China 2010 Available at: http://data.stats.gov.cn/workspace/index? $\mathrm{m}=$ hgnd. Accessed May 20, 2014.

4. Chu LW, Chi I. Nursing homes in China. J Am Med Dir Assoc 2008;9:237-243.

5. National Health and Family Planning Commission of the People's Republic of China. CPC Central Committee and State Council suggestions about adjusting family planning of the People's Republic of China. Available at: http://www. nhfpc.gov.cn/jczds/s7952/201401/8dee4040ca2e4f1ea10e27c1aca8875d.shtml. Accessed February 17, 2014.

6. Chan HY, Pang SM. Quality of life concerns and end-of-life care preferences of aged persons in long-term care facilities. J Clin Nurs 2007;16:2158-2166.

7. Chu LW, Luk JK, Hui E, et al. Advance directive and end-of-Life care preferences among Chinese nursing home residents in Hong Kong. J Am Med Dir Assoc 2011;12:143-152.

8. Chan CL, Chow AY. Death, Dying and Bereavement: The Hong Kong Chinese Experience. Hong Kong: Hong Kong University Press; 2006.

9. Ke LS. Advance care planning in Taiwan. Patient Educ Couns 2012;89:213.

10. Lush D. Advance directives and living wills. J R Coll Physicians Lond 1993;27: 274-277.
11. Department of Health UK. Available at: http://webarchive.nationalarchives gov.uk/+/www.dh.gov.uk/en/Publicationsandstatistics/Bulletins/theweek/Chie fexecutivebulletin/DH_4108436. Accessed January 19, 2013.

12. Department of Health and Ageing, Australian government. Available at: http:/ www.health.gov.au/internet/main/publishing.nsf/Content/mental-pubs-i-carertoc $\sim$ mental-pubs-i-carer-3 $\sim$ mental-pubs-i-carer-3-4. Accessed January 19, 2013.

13. White PD. The role of the critical care nurse in counseling families about advance directives. Crit Care Nurs Clin North Am 1997;9:53-61.

14. Robertson GS. Making an advance directive. BMJ 1995;310:236-238.

15. Wolf SM, Boyle P, Callahan D, et al. Sources of concern about the Patient SelfDetermination Act. N Engl J Med 1991;325:1666-1671.

16. Pasman HR, Wolf JE, Hesselink BA, et al. Policy statements and practice guidelines for medical end-of-life decisions in Dutch health care institutions: Developments in the past decade. Health Policy 2009;92:79-88.

17. Ministry of Health, Singapore. Available at: http://www.moh.gov.sg/content/moh web/home/legislation/legislation_and_guidelines/advance_medical_directiveact. html. Accessed January 20, 2013.

18. The Hong Kong Law Reform Commission of Hong Kong, HKSAR Government Substitute Decision-making and Advance Directives Sub-committee Consulting Paper. Available at: http://www.hkreform.gov.hk/tc/docs/decisions-c.pdf. Accessed January 20, 2013.

19. Fang HF, Jhing HY, Lin CC. Ethical issues in the practice of advance directives, living wills, and self-determination in end of life care. Hu Li Za Zhi 2009;56:17-22.

20. Chao CS. Development and prospects of hospice palliative care in Taiwan. Hu Li Za Zhi 2009;56:5-10.

21. Beijing Advance Directive Promotion Association, Peoples' Republic of China. Available at: http://www.xzyzy.com/page/jiaoyuzhongxin/xinwen/2013/0726/ 301.html. Accessed July 31, 2013.

22. Chi L, Boey KW. Hong Kong validation of measuring instruments of mental health status of the elderly. Clin Gerontol 1993;13:35-51.

23. Chi I, Leung EMF. Towards healthy ageing in Hong Kong. Hong Kong: St James' Settlement; 1995.

24. Chan HY, Pang SM. Validation of the modified quality-of-life in the end of life questionnaire for Chinese frail aged people [abstract]. Paper presented at: Conference on Quality of Life Research in Asia, 19-21 May, 2006; Hong Kong.

25. Low JA, Ng WC, Yap KB, et al. End-of-life issues-preferences and choices of group of elderly Chinese subjects attending a day care centre in Singapore. Ann Acad Med Singapore 2000;29:50-56.

26. Ivo K, Younsuck K, Ho YY, et al. A survey of the perspectives of patients who are seriously ill regarding end-of-life decisions in some medical institutions of Korea, China and Japan. J Med Ethics 2012;38:310-316.

27. Bowman KW, Singer PA. Chinese seniors' perspectives on end-of-life decisions. Soc Sci Med 2001:53:455-464.

28. Wang XS, Di LJ, Reyes-Gibby CC, et al. End-of-life care in urban areas of China: A survey of 60 oncology clinicians. J Pain Symptom Manage 2004;27:125-132.

29. Wilson DM. End-of-life care preferences of Canadian senior citizens with caregiving experience. J Adv Nurs 2000;31:1416-1421.

30. Ho ZJ, Radha Krishna LK, Yee CP. Chinese familial tradition and western influence: A case study in Singapore on decision making at the end of life. J Pain Symptom Manage 2010;40:932-937.

31. Kim SS, Lee WH, Cheon J, et al. Preferences for advance directives in Korea. Nurs Res Pract 2012;2012:873892.

32. Liu G, Gu D. Factors associated with place of death among Chinese oldest-old. Paper presented at: The annual meeting of the American Sociological Association; Aug 12, 2005; Philadelphia, PA. Available at: http://citation.allacademic. com/meta/p22654_index.html. Accessed December 10, 2013.

33. Yang L, Sakamoto N, Marui E. A study of home deaths in Japan from 1951 to 2002. BMC Palliat Care 2006;5:2.

34. Evangelista LS, Motie M, Lombardo D, et al. Does preparedness planning improve attitudes and completion of advance directives in patients with symptomatic heart failure? J Palliat Med 2012;15:1316-1320.

35. Kelley AS, Wenger NS, Sarkisian CA. Opiniones: End-of-life care preferences and planning of older Latinos. J Am Geriatr Soc 2010;58:1109-1116.

36. Sahm S, Will R, Hommel G. Attitudes towards and barriers to writing advance directives amongst cancer patients, healthy controls, and medical staff. J Med Ethics 2005;31:437-440.

37. Ko E, Berkman CS. Advance directives among Korean American older adults: Knowledge, attitudes, and behavior. J Gerontol Soc Work 2012;55:484-502.

38. Gordon NP, Shade SB. Advance directives are more likely among seniors asked about end-of-life care preferences. Arch Intern Med 1999;159:701-704.

39. Tajouri TH, Ottenberg AL, Hayes DL, et al. The use of advance directives among patients with implantable cardioverter defibrillators. Pacing Clin Electrophysiol 2012;35:567-573.

40. Halpern NA, Pastores SM, Chou JF, et al. Advance directives in an oncologic intensive care unit: A contemporary analysis of their frequency, type, and impact. J Palliat Med 2011;14:483-489.

41. Dunlay SM, Swetz KM, Mueller PS, et al. Advance directives in community patients with heart failure. Circ Cardiovasc Qual Outcomes 2012;5:283-289.

42. Sommer S, Marckmann G, Pentzek M, et al. Advance directives in nursing homes. Dtsch Arztebl Int 2012;109:577-583. 